\title{
MICROSTRUCTURAL EVOLUTION OF ATI 718PIUS® CONTOURED RINGS WHEN EXPOSED TO HEAT TREATMENT PROCEDURES
}

\author{
Octavio Covarrubias $^{1}$ \\ ${ }^{1}$ Frisa Aerospace SA de CV, Valentin G Rivero 200, Col. Los Trevino, Santa Catarina, Nuevo \\ León, 66150, Mexico. E-mail: ocovarrubias@ frisa.com
}

Keywords: 718Plus®, forging, heat-treatment.

\begin{abstract}
ATI 718Plus ${ }^{\circledR}$ is a nickel-base superalloy designed to promote excellent high temperature strength and thermal stability at elevated temperatures. Beside these properties, this material presents superior formability during forging operations, making ATI 718Plus® a suitable material for the manufacture of non-rotating and rotating components for jet engines and landbased turbines. Ring-rolling of rings is the natural option for the manufacture of such components, increasing material strength and reducing input weight. Use of contoured shapes simplifies and improves manufacturing processes, reducing machining touch time and in some cases, eliminating welding operations. This contribution summarizes results when ATI 718Plus® contoured rings are produced by ring-rolling operations and exposed to selected solution and precipitation heat treatments. Microstructural characteristics and mechanical properties are reported, including tensile testing at room temperature, tensile testing at elevated temperature, hardness and stress-rupture testing. Microstructural evaluations were performed by optical microscopy and electronic microscopy.
\end{abstract}

\section{Introduction}

Performance improving of jet-engines and land-based turbines for energy generation is a constant for nowadays designers. Use of better and more capable materials to reach this objective is an important strategy, where superalloys have a primordial role. Superalloy ATI 718Plus ${ }^{\circledR}$ is emerging as a viable material for the manufacture of components to be used in jet-engines and land-based turbines. This material is a precipitation hardened nickel-base alloy designed to have excellent stability and metallurgical properties at elevated temperature in combination with good processing properties [1].

ATI Allvac is leading a complete program, joining research centers, manufacturing operations and OEM's, to characterize and validated properties and capabilities of ATI 718Plus ${ }^{\circledR}$ in order to consider this superalloy as an appropriate material for the design and manufacture of components to be installed in jet-engines and land-based turbines for energy generation [2]. Some of these components can be produced by ring-rolling processing, which is a manufacture option that promotes important metallurgical benefits as grain size control and superior mechanical characteristics.

Ring-rolling operations include use of specialized tooling to produce contoured shapes. Contoured rings can provide complex shapes and its implementation leads to a reduction of input 
weight, improving of machining touch times and, in some cases, elimination of welding operations. Manufacturing parameters such as temperature, deformation ratios and deformation rates are determined and controlled to have a robust and reliable process. Considering the processing of most superalloys, mentioned parameters have important effects in ATI 718Plus ${ }^{\circledR}$ microstructure and mechanical properties. Figure 1 shows a ring-rolling operation for a contoured ring.

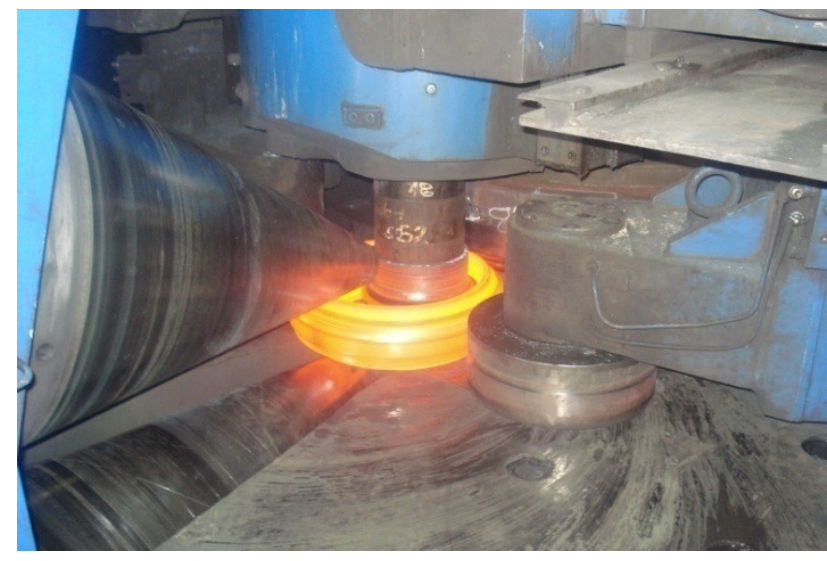

Figure 1: Ring-rolling of a contoured ring. (Frisa Aerospace SA de CV courtesy).

A better understanding of ATI 718Plus $®$ behavior will give designers key information about its capabilities and possible applications. Extensive research is done in this field [3, 4, 5, 6, 7]. This manuscript is a contribution to these efforts.

\section{Experimental Procedure}

A VIM+VAR $203.0 \mathrm{~mm}$ diameter billet was selected to extract several increments for the production of contoured rings with a weight of $80.0 \mathrm{~kg}$ and dimensions: $560.0 \mathrm{~mm}$ outer diameter, $455.0 \mathrm{~mm}$ internal diameter and $150.0 \mathrm{~mm}$ height. Table I summarizes the chemical composition of the starting material.

Table I: Chemical Composition of 718Plus ${ }^{\circledR}$ Starting Material

\begin{tabular}{|l|c|c|c|c|c|c|c|c|c|c|}
\hline Chemistry & $\mathrm{C}$ & $\mathrm{Cr}$ & $\mathrm{Mo}$ & $\mathrm{W}$ & $\mathrm{Co}$ & $\mathrm{Fe}$ & $\mathrm{Nb}$ & $\mathrm{Ti}$ & $\mathrm{Al}$ & $\mathrm{Ni}$ \\
\hline$\%$ w/w & 0.020 & 17.88 & 2.69 & 1.03 & 9.15 & 9.72 & 5.48 & 0.76 & 1.51 & $\mathrm{Bal}$. \\
\hline
\end{tabular}

Extracted segments were forged and rolled considering production parameters. Involved temperatures for hot-working operations were between $950^{\circ} \mathrm{C}$ and $1200^{\circ} \mathrm{C}$. Contoured rings were cut and segments exposed to the heat treatment conditions listed in Table II. Some of such segments were ring slices used for grain size mapping after forging operations and after each heat treatment operation.

Samples from the "as forge" condition and from each heat treatment condition were evaluated by optical microscopy in order to determine grain size evolution. Characterization of samples, relative to the presence of precipitates, was evaluated by scanning electron microscopy.

Mechanical testing including tensile at room temperature, tensile at elevated temperature, hardness and stress-rupture, was performed on heat treated samples. Elevated tensile testing was 
performed at $704^{\circ} \mathrm{C}$. Stress-rupture testing was performed at $704^{\circ} \mathrm{C}$, initial load of $621 \mathrm{MPa}$; after 39.0 hours of testing incremental loading was performed with increments of $34.5 \mathrm{MPa}$ at intervals of 8.0 hours.

Table II: Heat Treatment Conditions for ATI 718Plus ${ }^{\circledR}$ Ring Segments.

\begin{tabular}{|c|c|l|}
\hline Condition & Solution heat treatment & Precipitation heat treatment \\
\hline HT1 & $950^{\circ} \mathrm{C} / 2 \mathrm{hr} /$ Air-cooling & $\begin{array}{l}788^{\circ} \mathrm{C} / 8 \mathrm{hr} / \text { furnace cooling to } 704^{\circ} \mathrm{C}+ \\
704^{\circ} \mathrm{C} / 8 \mathrm{hr} / \text { Air-cooling }\end{array}$ \\
\hline HT2 & $980^{\circ} \mathrm{C} / 2 \mathrm{hr} /$ Air-cooling & $\begin{array}{l}788^{\circ} \mathrm{C} / 8 \mathrm{hr} / \text { furnace cooling to } 704^{\circ} \mathrm{C}+ \\
704^{\circ} \mathrm{C} / 8 \mathrm{hr} / \text { Air-cooling }\end{array}$ \\
\hline HT3 & $1010^{\circ} \mathrm{C} / 2 \mathrm{hr} /$ Air-cooling & $\begin{array}{l}788^{\circ} \mathrm{C} / 8 \mathrm{hr} / \text { furnace cooling to } 704^{\circ} \mathrm{C}+ \\
704^{\circ} \mathrm{C} / 8 \mathrm{hr} / \text { Air-cooling }\end{array}$ \\
\hline
\end{tabular}

\section{Results and Discussion}

Evaluation of samples after hot-working operations, or "as forge" condition, revealed a uniform fully re-crystallized microstructure. The microstructure is a consequence of the forging/rolling parameters considered for ring manufacture. Reported average grain size is 44.9 micron (ASTM 6.0). A uniform microstructure along the transversal section of each segment was observed, despite their contoured shape.

Samples exposed to condition HT1 reported an average grain size of 37.8 micron (ASTM 6.5). Limited or null grain coarsening was evident after solution treatment at $950^{\circ} \mathrm{C}$. When ATI 718Plus ${ }^{\circledR}$ segments were exposed to condition HT2 with a solution temperature of $980^{\circ} \mathrm{C}$, some grain size coarsening is observed. For this condition, average grain size was reported as 53.4 micron (ASTM 5.5).

For those segments exposed to heat treatment conditions of HT3, where a solution temperature of $1010^{\circ} \mathrm{C}$ is considered, grain coarsening is evident: reported average grain size is 63.5 micron (ASTM 5.0). Figure 2 summarizes grain size evolution when ATI 718Plus ${ }^{\circ}$ superalloy is forged and then exposed to heat treatment conditions. It is evident that as solution temperature is increased from $950^{\circ} \mathrm{C}-1010^{\circ} \mathrm{C}$, the alloy tends to increase its average grain size.

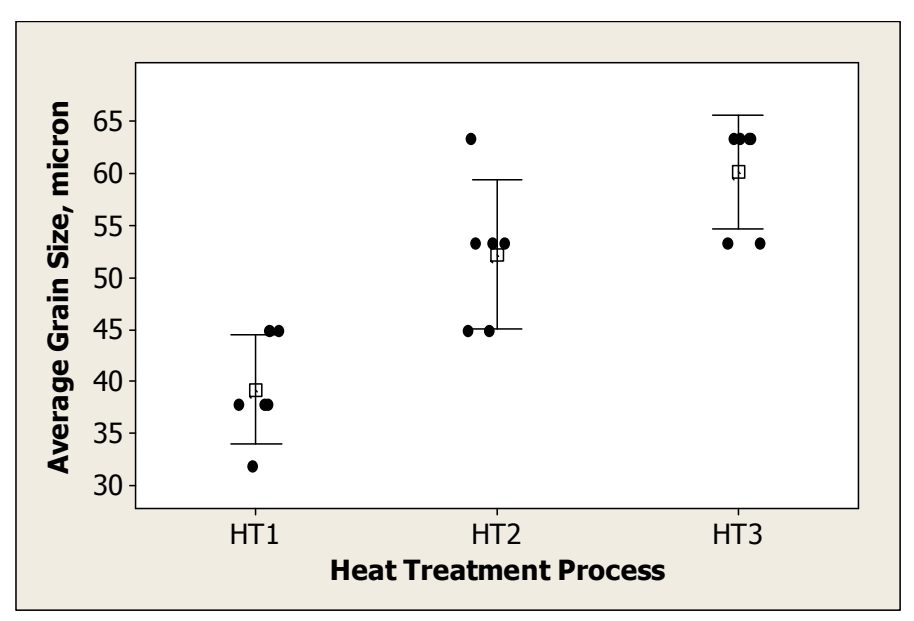

Figure 2: Grain size evolution for ATI 718Plus ${ }^{\circledR}$ when exposed to heat treatment procedures. 
A lack of delta-phase precipitates was observed by electronic microscopy for the "as forge" sample condition, i.e. after hot working operations. When rolled sample material was exposed to condition HT1, delta precipitates were evident at the grain boundaries.

As rolled samples exposed to heat treatment HT2 developed delta-phase at grain boundaries; their quantity and size is reduced when compared with samples exposed to HT1 condition. Samples exposed to condition HT3, developed a microstructure free of evident delta precipitates at grain boundaries, since the alloy was solution treated above the delta solvus temperature. Another characteristic of HT3 is a smooth texture on grain boundaries. Figure 3 present representative images of microstructures exposed to mentioned conditions.
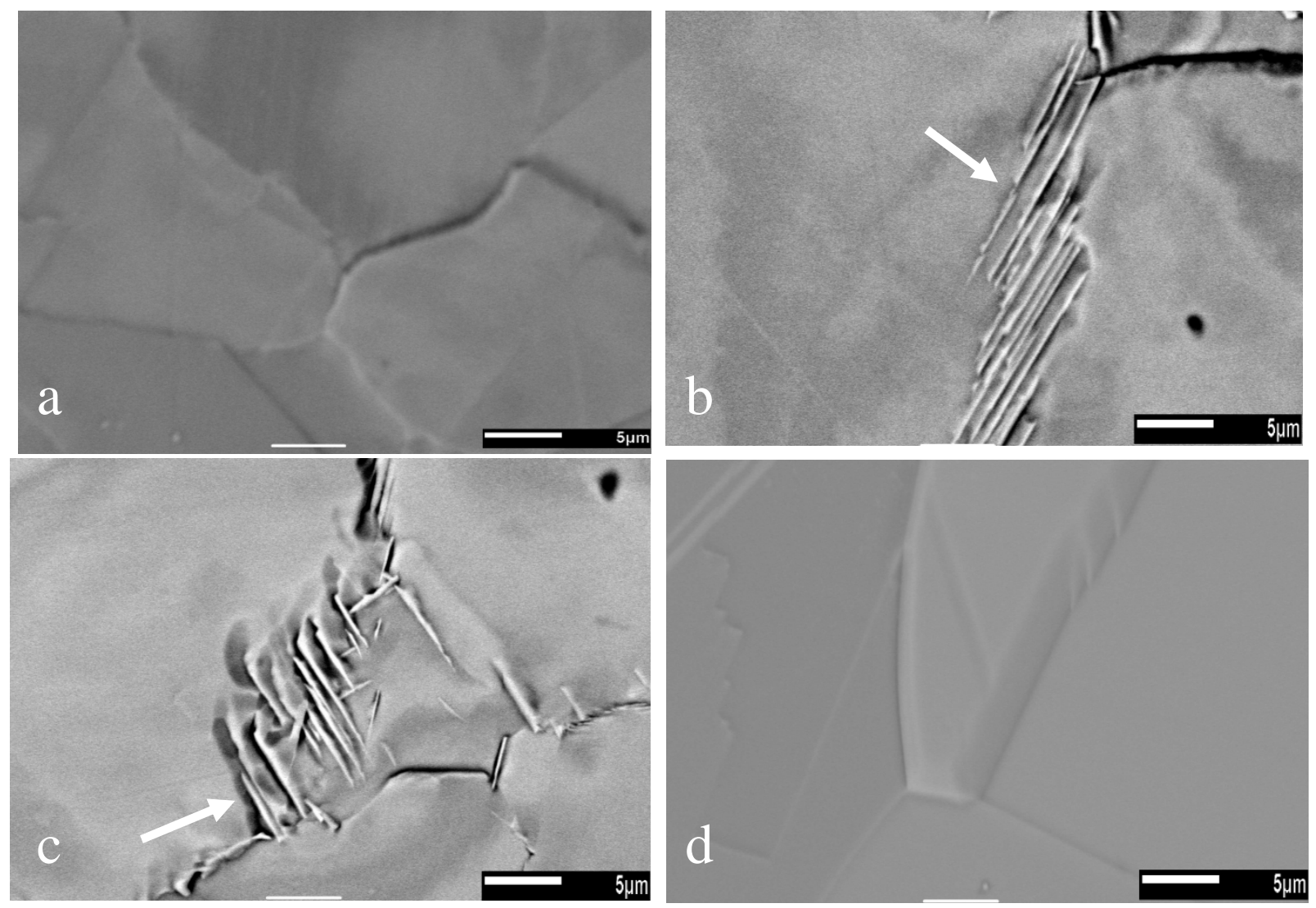

Figure 3: Representative microstructures of ATI 718Plus ${ }^{\circledR}$ alloy: a) Microstructure after rolling operations. b) Microstructure exposed to HT1 heat treatment (arrow indicates delta-phase precipitates at grain boundary). c) Microstructure of ATI 718Plus ${ }^{\circledR}$ alloy exposed to HT2 heat treatment (arrow indicates limited delta-phase precipitates at grain boundary). d) Microstructure of alloy exposed to HT3 heat treatment, no evident delta-phase precipitates at grain boundaries can be observed. 
The effect of solution condition is reflected by ATI 718Plus ${ }^{\circledR}$ behavior when tensile properties are evaluated. A drop on tensile properties was observed as a function of increasing solution temperature: as samples were exposed to $950^{\circ} \mathrm{C}, 980^{\circ} \mathrm{C}$ and $1010^{\circ} \mathrm{C}$ temperatures for HT1, HT2 and HT3 heat treatment conditions, lower tensile properties were promoted at room temperature and elevated temperature. All samples exposed to $1010^{\circ} \mathrm{C}$ during solution process of HT3 condition failed AMS 5441 and AMS 5442 yield strength requirements at room temperature and elevated temperature testing.

An adequate microstructure for ATI 718Plus ${ }^{\circledR}$ alloy must consist of re-crystallized grains with delta-phase precipitates present at grain boundaries. Precipitates of gamma prime are promoted during precipitation procedures and they are responsible for alloy strengthening. During solution operations, delta-phase precipitates at grain boundaries and has a more important effect on stress rupture properties, which will be discussed later.

Tensile results at room temperature reveal the effect of solution temperature for each of the three heat treatment procedures: as solution temperature is increased, tensile properties tend to diminish as average grain size is coarsened and the precipitation of delta-phase is inhibited. It is interesting to note the reduction of area (R/A) properties at room temperature as solution temperature is increased. This behavior can be related to limited formation of delta-phase precipitates at grain boundaries. Figure 4, Figure 5 and Figure 6 summarize reported results.
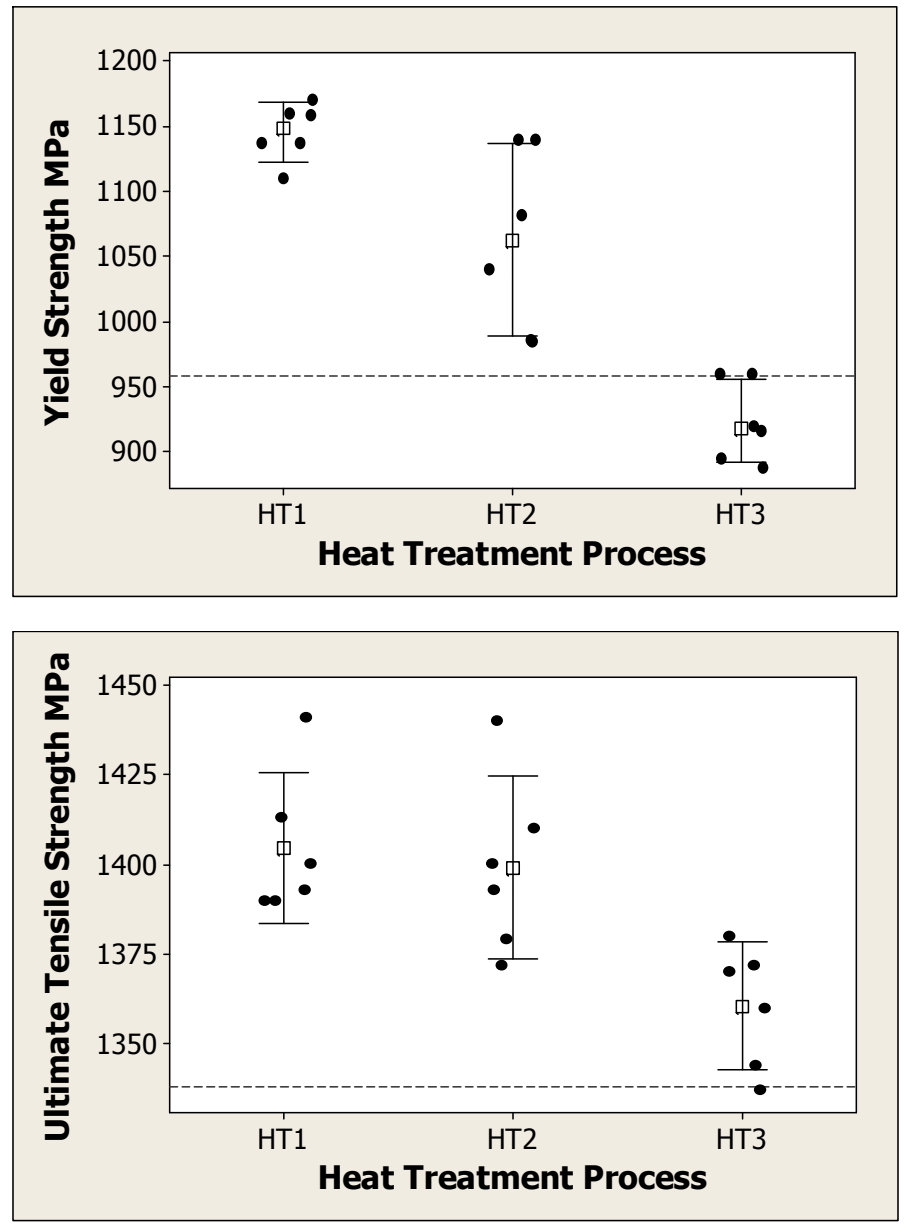

Figure 4: ATI 718Plus® YS properties at room temperature after solution and precipitation procedures. Minimum requirement per AMS 5441 and AMS 5442 is $958 \mathrm{MPa}$ (dashed line).

Figure 5: ATI 718Plus ${ }^{\circledR}$ UTS properties at room temperature after solution and precipitation procedures. Minimum requirement per AMS 5441 and AMS 5442 is $1138 \mathrm{MPa}$ (dashed line). 

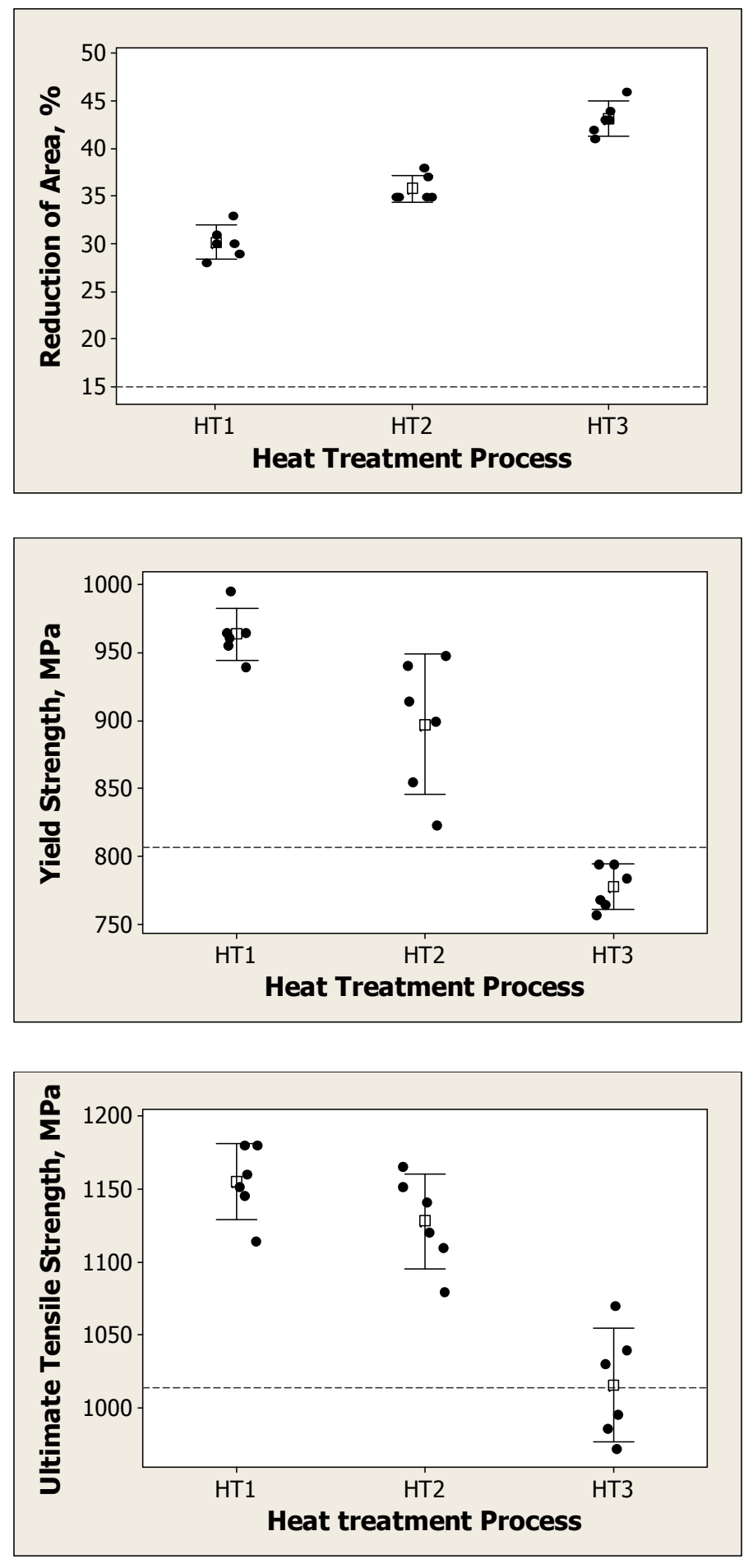

Figure 6: ATI 718Plus® reduction of area properties at room temperature after solution and precipitation procedures. Minimum requirement per AMS 5441 and AMS 5442 is $15.0 \%$ (dashed line).

Figure 7: ATI 718Plus ${ }^{\circledR}$ YS properties at $704^{\circ} \mathrm{C}$ after solution and precipitation procedures. Minimum requirement per AMS 5441 and AMS 5442 is $807 \mathrm{MPa}$ (dashed line).

Figure 8: ATI 718Plus® UTS properties at $704{ }^{\circ} \mathrm{C}$ after solution and precipitation procedures. Minimum requirement per AMS 5441 and AMS 5442 is $1014 \mathrm{MPa}$ (dashed line).

A similar behavior of tensile properties is observed at $704^{\circ} \mathrm{C}$ : tensile properties tend to diminish as alloy ATI 718Plus $®$ is exposed to higher solution temperatures of the involved heat treatment processes. Figure 7, Figure 8 and Figure 9 present reported tensile properties at elevated temperature testing. Reported ATI 718Plus ${ }^{\circledR}$ behavior of reduction of area (R/A) properties at elevated temperature are consistent, but with an inverse slope tendency to that reported for the 
room temperature testing showed in Figure 6. Further analyses need to be considered in order to explain this behavior.

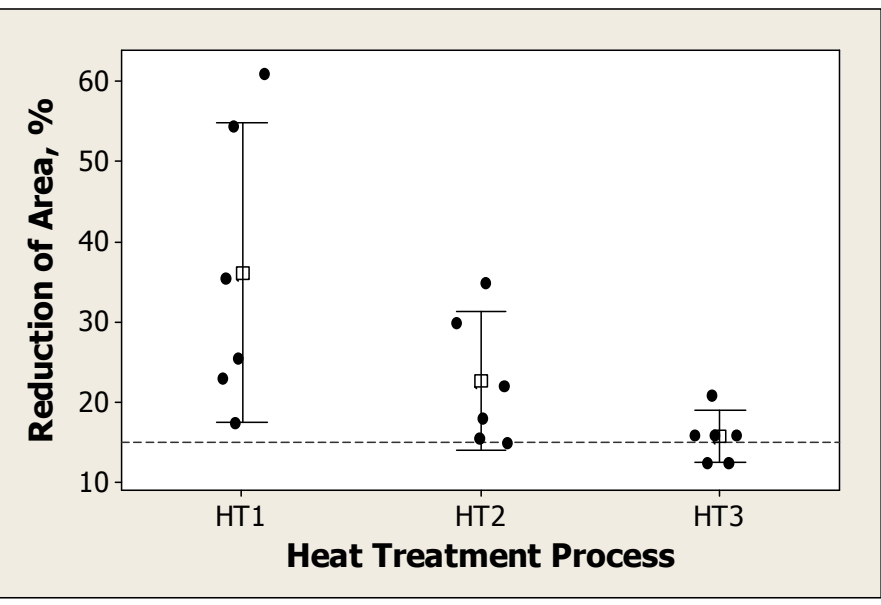

Figure 9: 718Plus ${ }^{\circledR}$ reduction of area properties at $704^{\circ} \mathrm{C}$ after solution and precipitation procedures. Minimum requirement per AMS 5441 and AMS 5442 is $15.0 \%$ (dashed line).

Effect of heat treatment procedures on ATI Allvac 718Plus ${ }^{\circledR}$ of reported hardness values can be summarized by Figure 10. In general, it can be observed that as solution temperature is increased, a reduction on hardness is detected by hardness testing. Minimum requirement for this property is $331 \mathrm{HBW}$ for the precipitated condition considering AMS 5441 and AMS 5442.

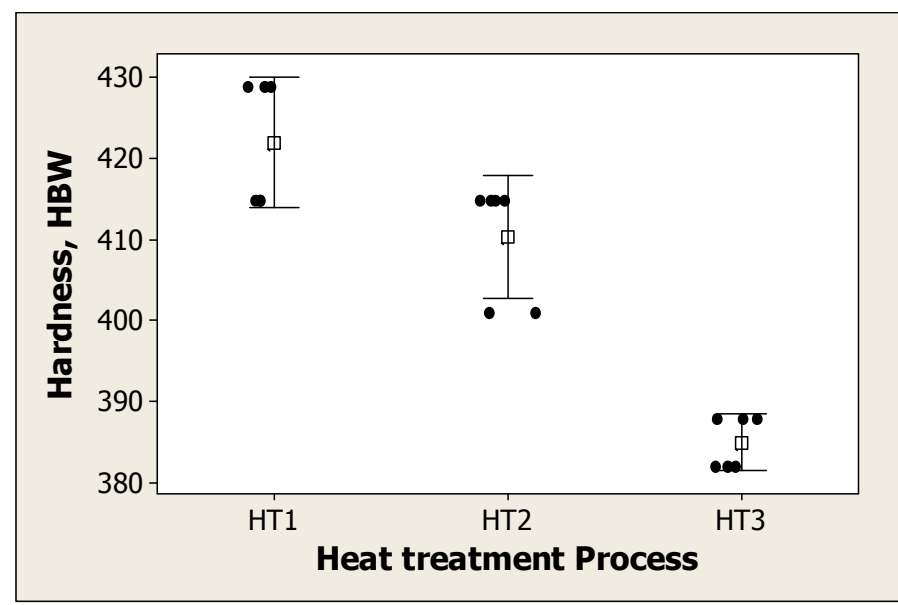

Figure 10: Hardness values reported for ATI 718Plus® after solution and precipitation procedures.

Precipitated ATI 718Plus ${ }^{\circledR}$ presented a stress-rupture behavior similar to other nickel-base superalloys: samples extracted from prototypes exposed to heat treatment HT1 present a finer average grain-size and an important promotion of delta-phase precipitates at grain boundaries, developing better stress-rupture properties.

Segments of ATI 718Plus ${ }^{\circledR}$ exposed to HT2 heat treatment procedure report a coarsened average grain-size and a limited formation of delta-phase precipitates at grain boundaries as a result of higher solution temperature. For this condition, two failures were reported indicating described microstructural characteristics could limit stress-rupture capabilities. 
Stress-rupture samples extracted from ATI 718Plus ${ }^{\circledR}$ exposed to HT3 heat treatment conditions presented the coarser average grain-size and absence of delta-phase precipitates at grain boundaries. All samples with this microstructure failed stress-rupture tests, confirming the importance of a fine average grain-size and presence of delta-phase precipitates at grain boundaries for 718Plus ${ }^{\circledR}$ alloy when it is evaluated per AMS 5441 or AMS 5442. A summary of these results can be visualized by Figure 11. Figure 12 presents elongation results for stressrupture experiments performed.

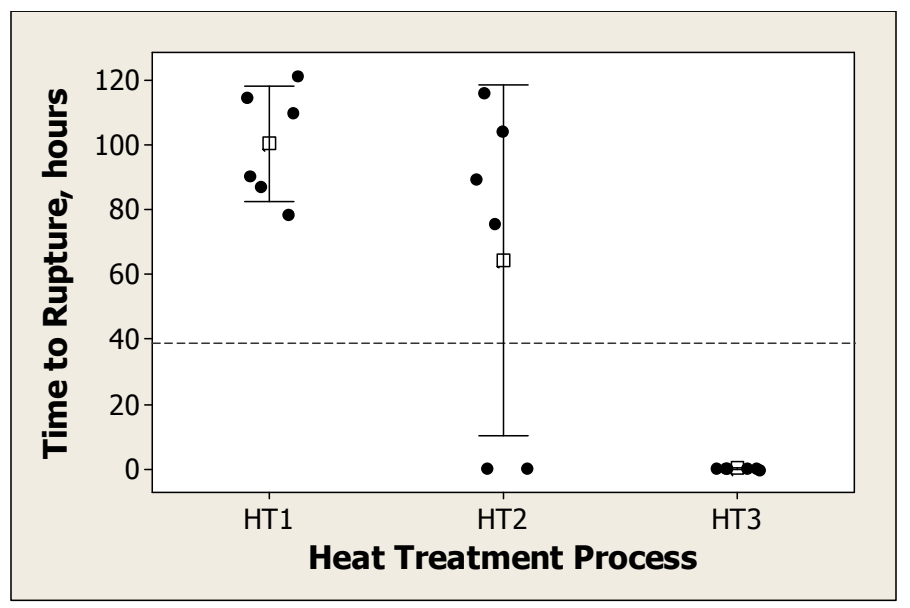

Figure 11: 718Plus ${ }^{\circledR} \quad$ stress-rupture properties at $704^{\circ} \mathrm{C}$ and incremental loading after solution and precipitation procedures. Requirement per AMS 5441 and AMS 5442 is 39.0 hours as minimum time to rupture (dashed line).

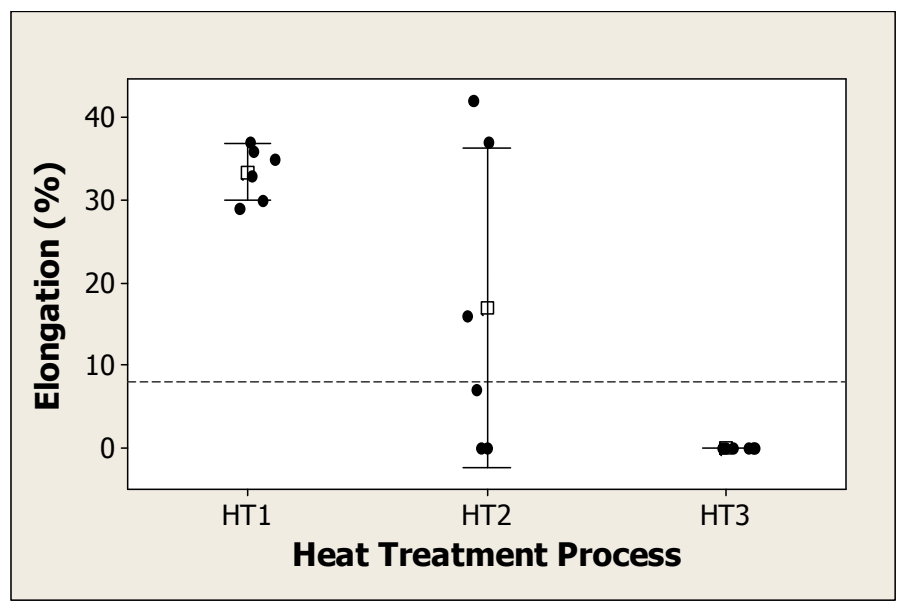

Figure 12: 718Plus® elongation for stress-rupture properties at $704^{\circ} \mathrm{C}$ and incremental loading after solution and precipitation procedures. Minimum requirement per AMS 5441 and AMS 5442 is $8.0 \%$ (dashed line).

\section{Conclusions}

Based on this study, it is possible to conclude:

a) Production of contoured rings with ATI 718Plus ${ }^{\circledR}$ for aerospace and energy generation application is feasible.

b) Thermo-mechanical processing of superalloy alloy ATI 718Plus® has substantive effects in microstructural and mechanical properties.

c) For the conditions evaluated, a good balance of mechanical properties can be obtained with an average grain size of 37.8 micron (ASTM 6.5) for ATI Allvac 718Plus ${ }^{\circledR}$.

d) For the heat treatments evaluated, delta-phase at grain boundaries can be heavily promoted when alloy is exposed to $950^{\circ} \mathrm{C}$. 


\section{References}

1. ATI 718 Plus ${ }^{\circledR}$ Alloy Data Sourcebook, Version 1.1, Allegheny Technologies Company, 2010, USA.

2. E.A. Ott, J. Groh \& H. Sizek, Metals Affordability Initiative: Application of Allvac Alloy 718Plus ${ }^{\circledR}$ for Aircraft Engine Static Structural Components, Superalloys 718, 625, 706 and Derivatives 2005, The Minerals, Metals \& Materials Society, 2005, USA.

3. X. Xie, C. Xu, G. Wang, J. Dong, W.D. Cao \& R. Kennedy, TTT Diagram of a Newly Developed Nickel-Base Superalloy- Allvac® 718Plus®, Superalloys 718, 625, 706 and Derivatives 2005, The Minerals, Metals \& Materials Society, 2005, USA.

4. R.A. Jeniski \& R.L. Kennedy, Development of ATI Allvac® 718Plus ${ }^{\circledR}$ Alloy and Applications 718, 625, 706 and Derivatives 2005, The Minerals, Metals \& Materials Society, 2005, USA.

5. W.D. Cao \& R.L. Kennedy, Recommendations for Heat Treating Allvac® 718Plus® Alloy Parts, ATI Allvac Research \& Development, 2006, USA.

6. X. Xie, C. Xu, G. Wang, J. Dong, W.D. Cao \& R. Kennedy, TTT Diagram of a New Developed Nickel-Base Superalloy Allvac ${ }^{\circledR}$ 718Plus ${ }^{\mathrm{TM}}$, Superalloys 718, 625, 706 and Derivatives 2005, The Minerals, Metals \& Materials Society, 2005.

7. R.L. Kennedy, W.D. Cao, T.D. Bayha \& R. Jeniski, Developments in Wrought Nb Containing Superalloys $\left(718+100^{\circ} \mathrm{F}\right)$, The Mineral, Metals \& Materials Society, 2003.

\section{Acknowledgments}

Frisa Aerospace SA de CV recognize Conacyt-Mexico support by INNOVAPYME project 110988 and contribution of R. Jeniski, S. Cox and E.T. McDevitt from ATI Allvac for the realization of this research. 